\title{
Computer Tomography in Disseminated Sclerosis
}

\author{
K. G. WARREN, M. J. BALL. D. W. PATY, AND M. BANNA
}

SUMMARY: A case is reported where the appearance of acute, diffuse, disseminated sclerosis on computer tomography $(\mathrm{Ct}$ scan) is described and the literature is reviewed. This disease may give rise to multiple, small areas of diminished $X$-ray absorption which may decrease in size during the course of the disease. The histological features of one of the lesions was correlated with the radiological findings. It is suggested that, perhaps, only during the active stage of demyelination can the lesions be detected on the $C t$ scan.

RÉSUMÉ: Compte rendu d'un cas de sclérose en plaques, aigu et diffuse sur la tomographice axiale avec ordinatear avec revue des publications sur le sujet. Cetre sclérose peut produire de maltiples petits foci oul l'absorbtion est diminuée avec rayons-X pendant la darée de la maladie. Les caractères histologiques ont été compares avec les donnés radiologiques. II semblerait que ce n'est peutêtre que dans la periode active de démyélinisation que les lésions peuvent être observées sur la tomographie axiale avec ordinateur.
From the Department of Clinical Neurological Sciences University Hospital, University of Western Ontario, London, Ontario and The Department of Radiology (Dr. Banna) McMaster University Medical Centre, Hamilton, Ontario.

Reprint requests to Dr. D. W. Paty, Department of Clinical Neurological Sciences. University Hospital, 339 Windermere Road, London, Ontario N6G $2 \mathrm{~K} 3$ Canada.

\section{REPORT OF A CASE}

The patient was a 29 year old twin who developed difficulty with vision in July, 1975. She became unable to read a newspaper or watch television with the same clarity to which she had been previously accustomed. At approximately the same time, it became more difficult for her to dress her eight-month-old son. By August of 1975, she had difficulty dressing herself: in that she would "get lost" while trying to put her housecoat on. A left homonymous hemianopsia was then present. At a local hospital, a brain scan showed bilateral deep parietal areas of increased uptake (Fig. 1). A bilateral carotid angiogram was normal.

She was transferred to the University Hospital, London, Ontario, Canada, where her clinical status

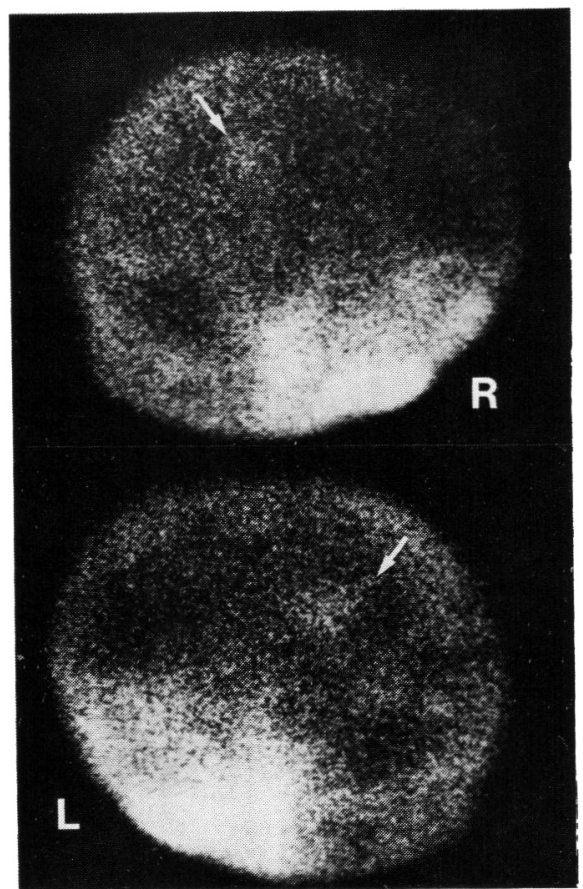

Figure $1-\mathrm{Tc}^{\mathbf{9 9 m}}$ brain scintigram: right and left lateral views showing small areas of high uptake in both parietal lobes (arrows). was characterized by dressing apraxia, constructional apraxia, difficulty with visual-spatial tasks, rightleft confusion, finger-agnosia, dyscalculia, and agraphia with dyslexia, as well as hesitancy of speech, left homonymous hemianopsia, astereognosis of her left hand, and some left-sided sensory inattention on simultaneous stimulation.

Initial studies showed the following tests to be normal: hemogram, reticulocyte count, erythrocyte sedimentation rate, bone marrow examination, urinalysis, electrolytes, serum enzymes and immunoglobulins, creatinine, bilirubin, antinuclear antibody, LE-preparation, $X$-rays of her skull and chest, intravenous pyelogiam, as well as liver and bone scans. Neoplastic disease could not be found in her chest, breasts, abdomen or pelvis. The cerebro-spinal fluid cell count and total protein assessment were normal.

A brain scan on August 22, 1975 , showed a focus of increased radioactivity deeply placed in the right parietal region. A repeat brain scan on September 5, 1975, showed the initial lesion as well as another area of increased activity in the left occipital region. A third brain scan on September 19, 1975, again showed these bilateral parietal lesions.

Electroencephalography on September 9,1975 , demonstrated a delta activity in the right parietaloccipital-posterior temporal and the left parietal-occipital regions (Fig. 2).

An initial Ct scan on September 4, 1975, revealed three areas of decreased density in the brain: one in each of the posterior parietooccipital regions, and a third in the right occipital region (Fig. 3). On September 18, 1975, a repeat Ct scan showed that the right occipital lesion had almost disappeared, but a small 


\section{AWAKE}

AGE 29
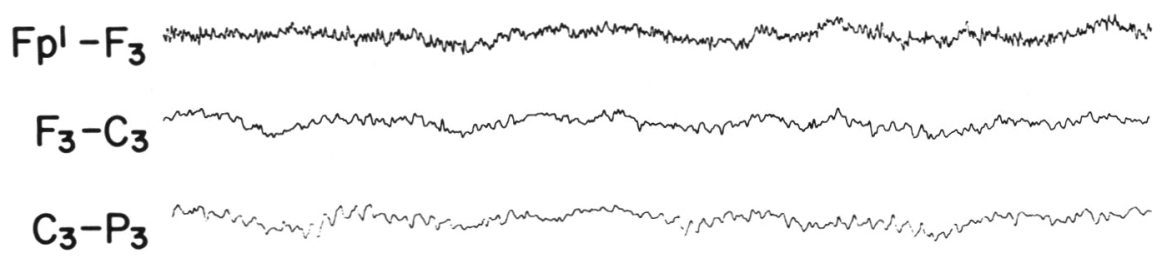

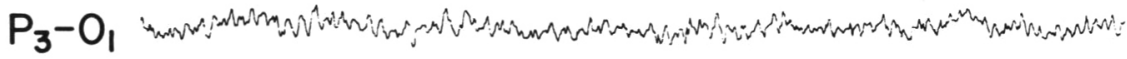
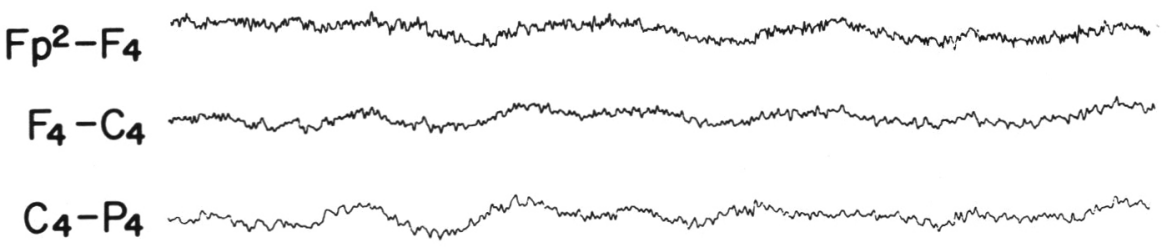

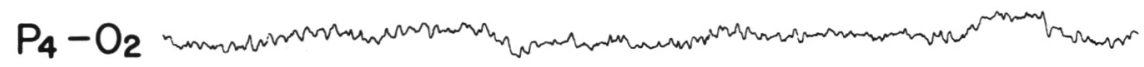

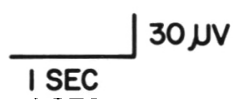

Figure 2-Electroencephalogram: depicting delta activity at right and left parietooccipital regions with reduction of alpha on the right. Slow waves in channels $1,2,5$, 6 , represent eye movement.

fresh lesion had now developed in the anterior part of the left frontal lobe (Fig. 4). The bilateral posterior parieto-occipital areas of radiolucency were still prevent.

On September 23, 1975, weakness developed on her right side. Within 24 hours the patient had developed numbness, tingling and weạkness of her right hand; and weakness of her right leg made getting up and down stairs difficult. Neurological examination now showed increased tone, increased deep tendon reflexes, and ankle clonus on the right side. The right abdominal reflexes were absent, and the right plantar response was equivocal. The weakness was particularly pronounced in the flexor muscles of the right leg. Proprioception was impaired in the right arm and leg, while vibration sense was normal. Mild astereognosis was also detected on the right side. Her gait was unsteady and she was unable to perform tandem walking. She was unsteady when standing with her feet close together and her eyes closed, but a Romberg's sign was not present.

A repeat cerebro-spinal fluid assessment showed normal cell count, glucose $77 \mathrm{mg} / \mathrm{dl}$, and protein 27 $\mathrm{mg} / \mathrm{dl}$. The cerebro-spinal fluid immunoglobulins were less than 5 $\mathrm{mg} / \mathrm{dl}$ (normal $<6 \mathrm{mg} / \mathrm{dl}$ ). Antimeasles antibody levels were not determined. There was no change in a repeat brain scan and an electroencephalogram. A third $\mathrm{Ct}$ scan on October 1, 1975, showed the bilateral parasagittal parietal lesions to be unchanged. A brain biopsy of cortex and white matter was performed on October 6, 1975, through a right parietal craniotomy.

In the latter part of October, 1975, the right leg became weaker while the patient was taking Dexamethasone $1.5 \mathrm{mg}$. four times each day. A brain scan repeated on October 28, 1975, showed only the left parietal abnormality. Electroencephalography on November 11, 1975, continued to show delta waves in the occipital areas, as well as the right parietal area. When re-assessed in
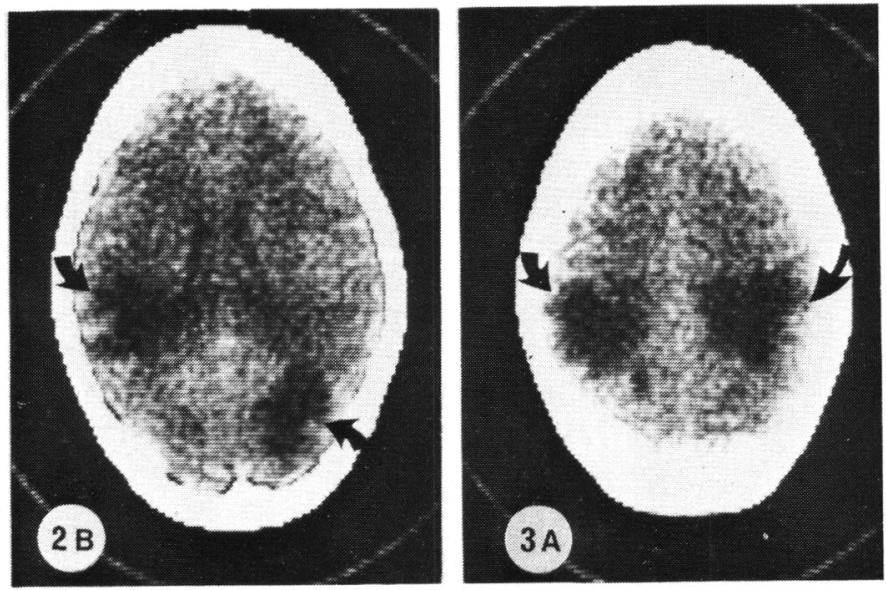

Figure 3-Ct scan (September 4, 1975) showing multiple areas of decreased X-ray absorption in the upper part of both parietal lobes and right occipital lobe (arrows). 2B and 3A refer to the level of the section, 5 and $6.3 \mathrm{~cm}$. above the orbitomeatal !ine.
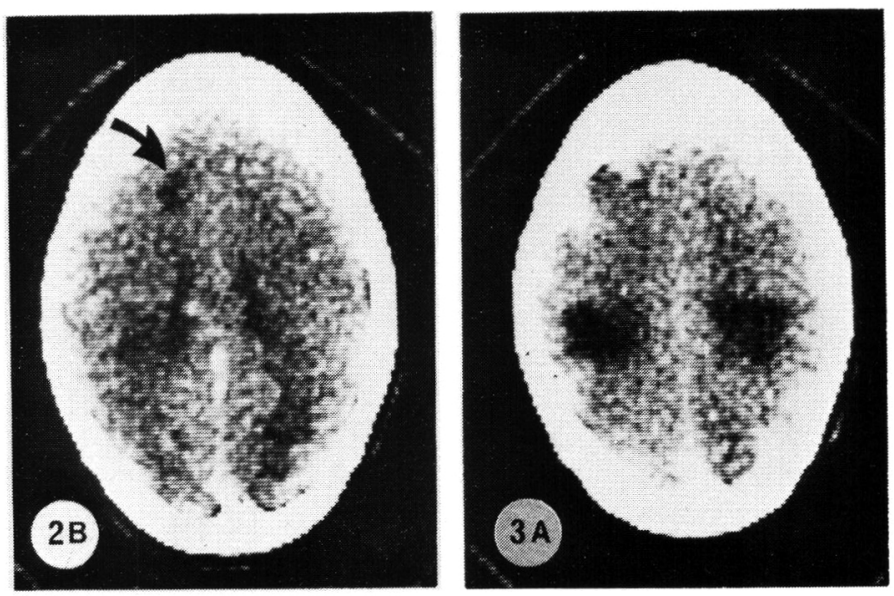

Figure 4-Ct scan at approximately the same levels as the preceding illustration and performed two weeks later. The lesions in slice 2B have almost disappeared and a fresh lesion (arrow) developed in the left frontal lobe. The lesions in slice $3 \mathrm{~A}$ are considerably smaller in size. 
early December, 1975, the patient had an unchanged clinical picture. Dressing apraxia, constructional apraxia, and visual-spatial disorientation indicated right parietal lobe dysfunction. The elements of Gerstmann's syndrome as well as loss of joint-position sense and of 2-point discrimination in her right hand indicated left parietal lobe dysfunction. The left homonymous hemianopsia persisted.

A generalized major motor seizure occurred in late December, 1975. She was placed on diphenylhydantoin. Over the next two months, there were no additional neurological features. However, in March, 1976, she awoke unable to see with her left eye. A diagnosis of retrobulbar neuritis was made.

Her twin sister did not develop similar symptoms or signs. There

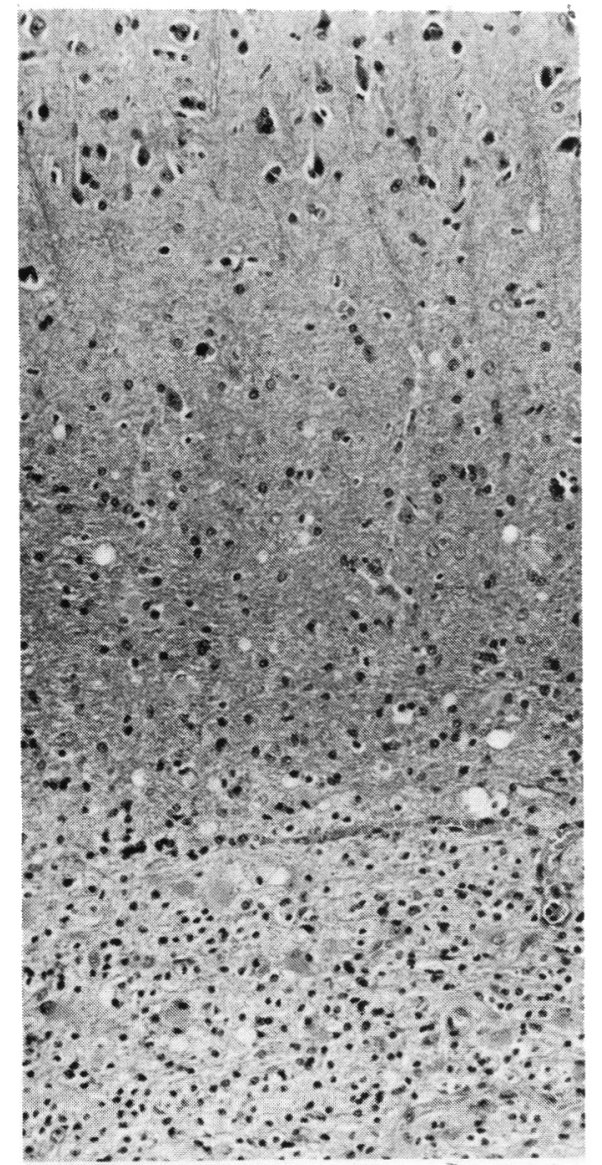

Figure 5-Photomicrograph of right parietal lobe biopsy. Normal cortex (top), spared subcortical "U" fibers (middle) and periphery of demyelinated area (bottom). $H$ and $E / L F B$, original magnification $\times 60$. was no family history of neurological degenerative disorders.

\section{Neuropathology}

Multiple portions of the parietal lobe biopsy were sectioned in paraffin; and special stains included hematoxylin and eosin-Luxol fast blue, Bodian silver, Periodic acidSchiff, Holzer and Lendrum phloxine-Tartrazine. A sample was also fixed in glutaraldehyde for electron microscopy.

Light microscopic examination demonstrated normal leptomeninges and cerebral cortex. Marked abnormalities were present in the white matter. A large area of demyelination was present with a sharp border of change to normal staining myelin. The demyelinated area spared some of the subcortical " $U$ " fibers (Fig. 5). Within the demyelinated area

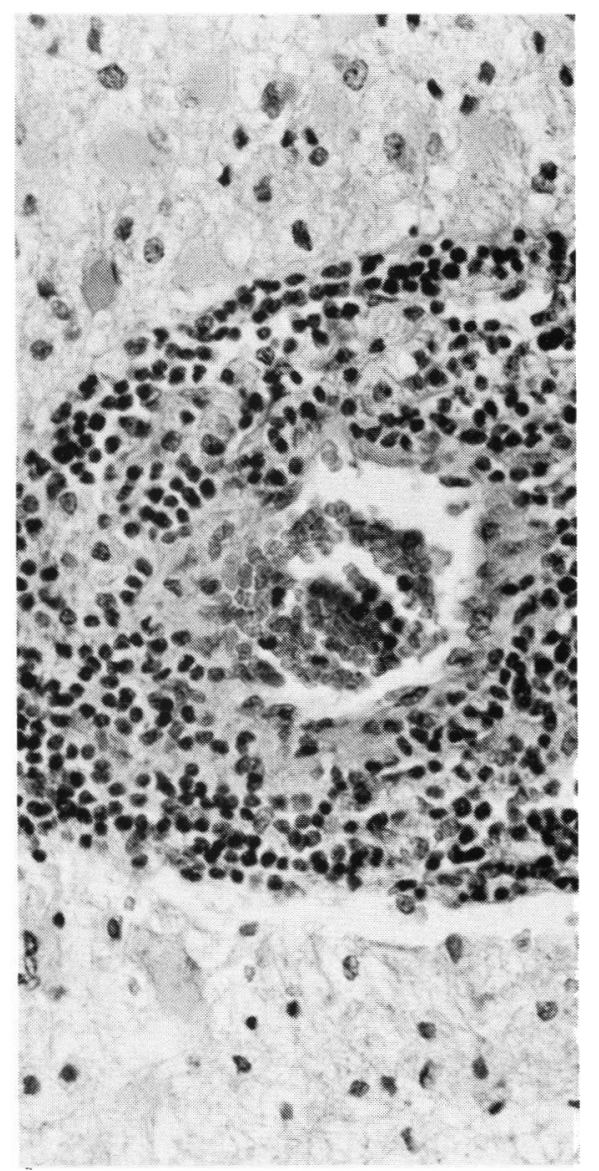

Figure 6-Photomicrograph from within the demyelinated area, showing perivascular cuffing by abundant lymphocytes and occasional histiocytes. $H$ and $E / L F B$, original magnification $x$ 150. there was abundant perivascular cuffing by lymphocytes (Fig. 6) and by foamy histiocytes. Perivascular lymphocytic cuffing was not present in the normal well-myelinated areas. The oligodendrocytes within the demyelinated area were degenerated with pyknotic nuclei and severely swollen "empty" cytoplasm. Large numbers of phagocytes containing breakdown products of myelin, and large reactive gemistocytic astrocytes were also present within the demyelinated area (Fig. 7). The tissue density of the demyelinated area was clearly reduced, and in some areas early pseudocystic degeneration was present (Fig. 8). Microglial proliferation and relative sparing of axons completed the histological details of the demyelinated area.

The area which stained for myelin was also abnormal. There were numerous plump reactive astrocytes within the myelinated zone. Pyknotic nuclei were infrequently seen in oligodendrocytes. Larger vesicular oligodendroglial nuclei were more abundant, especially in close proximity to capillaries.

Neither inclusion bodies nor virus-like particles could be identified on electron microscopy, despite extensive examination.

The histopathology was strikingly similar to an "active" plaque found in the right middle temporal gyrus of a patient who expired with classical disseminated sclerosis (Fig. 9). This patient also had multiple chronic gliotic plaques in the brain stem and spinal cord.

\section{COMMENT}

The appearance of the $\mathrm{Ct}$ scan in various intracranial lesions, other than demyelination, was first described by Ambrose $(1973,1974)$ and later by other authors (Baker et al., 1974; Banna, 1975 and 1976; Bogdanoff, 1975; Davis and Pressman, 1974; Houser et al., 1975; Kistler et al., 1975; Wortzman, 1975). Tissues that are greater in density than the grey matter or that contain elements of high atomic number absorb more radiation and appear greyish-white. Tissues with abundant water content, such as brain edema, infarction, cystic degeneration in tumors 
and intracranial cysts have a low density and appear darker than the surrounding brain. Following the intravenous injection of any watersoluble contrast medium, the density of many brain tumors is enhanced. This feature is rarely seen in cases of cerebral infarction and often helps in the differential diagnosis between neoplastic and non-neoplastic disease.

The $\mathrm{Ct}$ scan of this case showed multiple, low-density areas, of which two lesions in the parietal region were surprisingly symmetrical. There was no deformation or displacement of the ventricular system and none of the lesions was contrast enhanced. Nevertheless, because of their multiplicity and for lack of a better alternative, the possibility of cerebral metastases was considered. A thorough search for a primary tumor failed to support the diag-

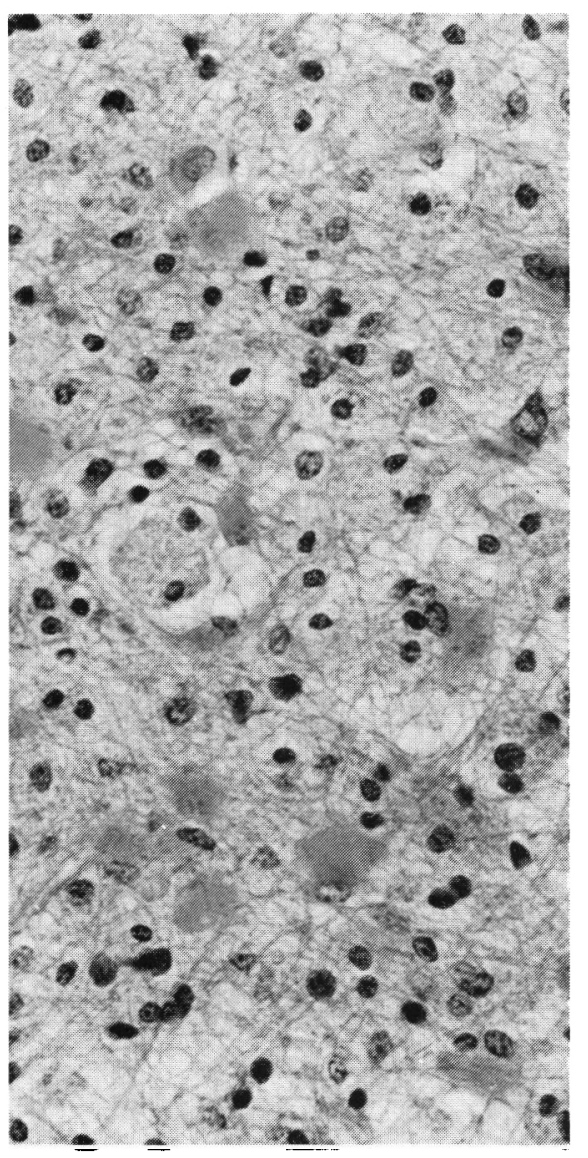

Figure 7-Photomicrograph of demyelinated area, exhibiting reactive astrocytes, gemistocytic astrocytosis and lipid-filled histiocytes. $\mathrm{H}$ and E/LFB, original magnification $\times 150$. nosis. When the $\mathrm{Ct}$ scan was repeated two weeks later, it was noted that one of the lesions had decreased in size. It was this observation which was radiologically suggestive of demyelination, although no similar case was found in the literature. Only two authors, Baker et al. (1974) and David and Pressman (1974), have commented on the value of the $\mathrm{Ct}$ scan in multiple sclerosis. Baker et al. performed $\mathrm{Ct}$ scans on eight patients with multiple sclerosis and of these, five had normal scans, two had parenchymal lesions and one showed evidence of cerebral atrophy. No mention of demyelinating plaques was made. Davis and Pressman stated that several patients with multiple sclerosis have shown small, lucent zones which did not displace the ventricular system. The features of these zones were not described and only in one case was

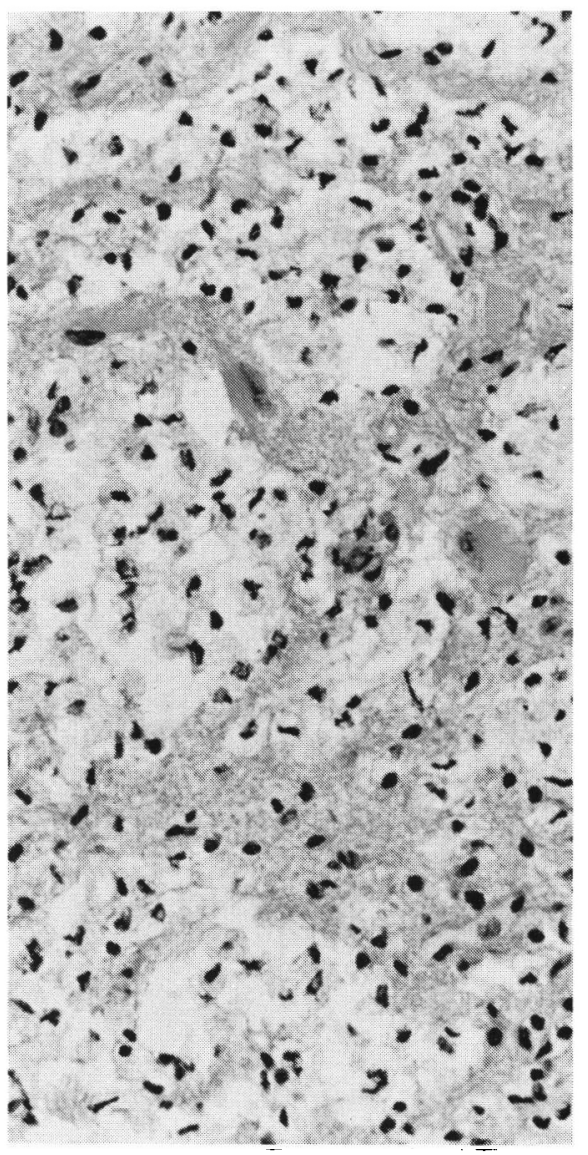

Figure 8-Photomicrograph of demyelinated area, with pseudocystic rarefaction, consistent with decreased tissue density, $H$. and E/LFB, original magnification $\times 150$. the nature of the lesion proven at brain biopsy. In three patients with multiple sclerosis, examined by one of us (M. Banna), the Ct scan was normal in one case, showed evidence of ventricular dilatation in a second case and in the third case there was a small, paraventricular zone of decreased density suggestive of demyelination (Fig. 10). This case, however, was not histologically proven.

In the present case, the clinical profile of parietal and occipital lobe symptoms and signs in addition to the neuropathological features suggest that the patient has a myelinoclastic process. The pathological features of myelinoclastic diseases have been summarized by Poser (1970). Our patient's twin sister is asymptomatic and functioning normally as a nurse. In addition, the patient herself was in good health until she sud-

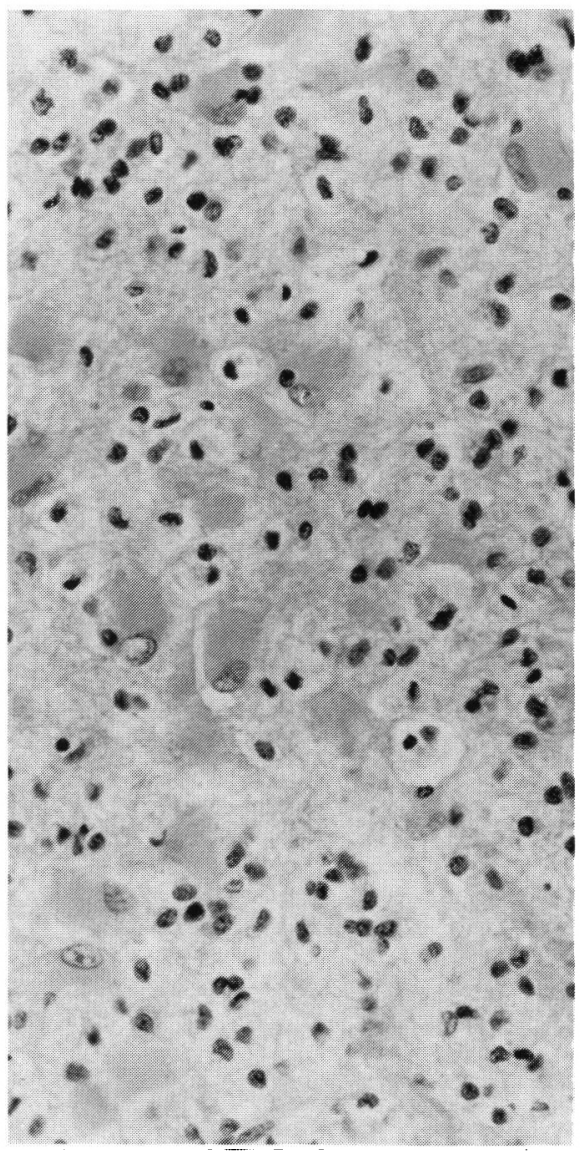

Figure 9-Photomicrograph from a classical case of multiple sclerosis showing similar appearances to those in the preceding illustration. 

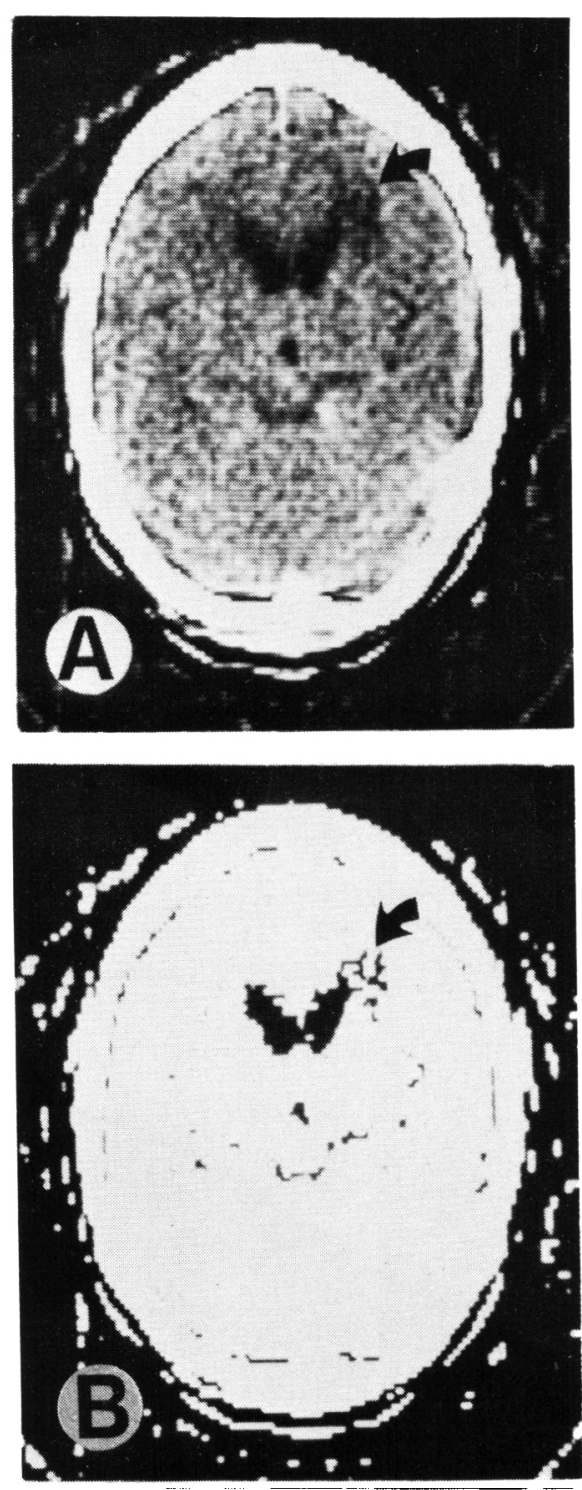

Figure $10-\mathrm{Ct}$ scan of a 46-year-old female patient with a long history of multiple sclerosis. A low density zone, probably representing an area of demyelination, is seen close to the frontal horn of the right lateral ventricle (arrow). (A) is the conventional scan and $(B)$ is to highlight the lesion. This case was not histologically proven.

denly developed the disease at 29 years of age, suggesting that myelinogenesis was normal. The parietal lobe biopsy showed a demyelinated area with sharply demarcated edges, irregular involvement of the subcortical " $U$ " fibers, gliosis with gemistocytic astrocytes, a perivascular inflammatory reaction, and vacuolated histiocytes containing myelin breakdown products. Similar pathology was probably pre- sent in the left parietal lobe, since the $\mathrm{Ct}$ scan showed bilateral areas of radiolucency in both parietal lobes. Since the histopathological features were similar to active plaques seen in multiple sclerosis, the patient was given a provisional diagnosis of diffuse-disseminated sclerosis. A definitive diagnosis of diffusedisseminated (transitional) sclerosis, as defined by Poser with unrelated plaques of myelinoclasia at other levels of the neuraxis can of course only be proven by complete pathological examination of the brain and spinal cord.

From the cases which we have seen and those in the literature by Baker et al. (1974) and by Davis and Pressman (1974), it appears that the $\mathrm{Ct}$ scan in cases of multiple sclerosis may be entirely normal. It may show small areas of decreased density within the white matter. These are roughly circular in shape. They are not contrast enhanced and they may decrease in size during the course of the disease. Neither the incidence of these lucent zones, nor their correlation with the clinical manifestations has been documented. Longstanding cases of demyelination may show evidence of cerebral atrophy. We feel that the $\mathrm{Ct}$ scan, at the present stage of its development, cannot be considered a reliable tool for the diagnosis of multiple sclerosis. This is because the numerical value on the computer print-out or the small squares that constitute the $\mathrm{Ct}$ image represent the mean absorption coefficient values of different tissues within a small volume measuring 1.5 $\times 1.5 \times 13 \mathrm{~mm}$. Thus, the low density of a demyelinating focus is integrated with the density of the surrounding brain and will be obscured. With the introduction of a smaller matrix $0.75 \times 0.75 \mathrm{~mm}$. (Ct 1010), our views may change. The reason that some lesions have been shown on the $\mathrm{Ct}$ scan must be related to the degree of brain edema. Perhaps it is only during the active stage of demyelination that the lesion may be discovered on the $\mathrm{Ct}$ scan. This, probably, also applies to isotope scintigraphy and accounts for the low incidence of positive scans in unselected cases of multiple sclerosis as reported by Gize and Mishkin (1970) and by Weisbaum and Garnet (1973).

Addendum: Following submission of this article for publication, the author became aware of a letter to the editor of Lancet (1976) i, 689 by $L$. A. Cala and F. L. Mastaglia entitled Computerized Axial Tomography in Multiple Sclerosis. Nineteen patients in whom a diagnosis of M.S. was established or felt to be probable on clinical grounds and on the basis of cerebrospinal-fluid findings and visual and spinal somatosensory evoked potentials were studied with an E.M.I. scanner using a $160 \times 160$ matrix; plain standard tomographic cuts of the cranium being taken in each case with additional cuts of the orbits in 4 of the cases. The findings were: normal (6), cerebral plaques (7), optic nerve plaques (3), and atrophy (4). Neuropathological confirmation of the disease was not provided.

\section{ACKNOWLEDGMENTS}

The authors wish to thank the following physicians for their co-operation and assistance: Dr. W. T. Blume, Dr. C. L. Dolman, Dr. D. Gilden, Dr. J. P. Girvin, Dr. A. Paul, Dr. C. M. Poser, and Dr. L. B. Rorke. The photographic illustrations were provided by Ms. V. Bruckschwaiger and Mr. M. Donnelly. Typing of the manuscript was done by Miss Eileen Disher.

\section{REFERENCES}

AMBROSE, J. (1973). Computerized transverse axial scanning (tomography): Part 2. Clinical application. Brit. J. Radiol. 46: 1023-1047.

AMBROSE, J. (1974). Computerized X-ray scanning of the brain. J. Neurosurg. 40: 679-695.

BAKER, H. L., CAMPBELL, J. K., HOUSER, D. W., REESE, D. F., SHEEDY, P. F., HOLMAN, C. B. and KURLAND, R. L. (1974). Computer assisted tomography of the head: an early evaluation. May Clinic Proc. 49: 17-27.

BANNA, M., MOLOT, M. J., KAPUR, P. L. and GROVES, J. (1975). Computer tomography of the brain in Hamilton. C.M.A.J. 113: 303-307.

BANNA, M. (1976). Interpretation of the Ct scan. The Can. J. of Neuro. Sciences. In press. 
BOGDANOFF, B. M., STAFFORD, C. R., GREEN, L. and GONZALEZ, C. F. (1975). Computerized transaxial tomography in the evaluation of patients with focal epilepsy. Neurology 25: 1013-1017.

DAVIS, D. O. and PRESSMAN, B. D. (1974). Computerized tomography of the brain. Radiol. Clinics. N. Am. 12: 297-313.

GIZE, R. W. and MISHKIN, F. S. (1970). Brain scans in multiple sclerosis. Radiology 97: 298-299.
HOUSER, D. W., SMITH, J. B., GOMEZ, M. R. and BAKER, H. L. (1975). Evaluation of intracranial disorders in children by computerized transaxial tomography: A preliminary report. Neurology 25: 607-613.

KISTLER, J. P., HOCHBERG, F. H., BROOKS, B. R., RICHARDSON, E. P., NEW, P. F. J. and SCHNUR, J. (1975). Computerized axial tomography: Clinicopathologic correlation. Neurology 25: 201-209.
POSER, C. M. (1970). Myelinoclastic diffuse and transitional sclerosis. In Vinken $\mathrm{PH}$, Bruyn GW (eds.): Handbook of Clinical Neurology 9: 469-484, Amsterdam, North Holland Publishing Co.

WORTZMAN, G. (1975). Computerized tomography of intracranial lesions. Med. Prog. 30: 1068-1073.

WEISBAUM, S. D. and GARNETT, E. S. (1973). Brain scan in Schilder's disease. J. Nuc. Med. 14: 291-292. 